\title{
Arbor
}

\section{Representantes españoles en el imperio Otomano, entre la diplomacia, la crónica y la literatura (1864-1886)}

\section{Pablo Martín Asuero}

Arbor CLXXX, 711-712 (Marzo-Abril 2005), 773-788 pp.

Se puede encontrar un cierto interés en el Mediterráneo oriental en España a partir de 1860. Una prueba de ello es la producción textual de varios diplomáticos españoles destinados en el imperio Otomano a través de las crónicas periodísticas y de la publicación de sus memorias las cuales se acercan a la literatura de viajeros. Adolfo de Mentaberry, Diego de Coello de Portugal, Antonio Bernal de O'Reilly o Manuel Quintana son un ejemplo de este tipo de diplomático de ideología liberal que transmitieron a los lectores del mundo en español la situación del imperio Otomano entre los años de 1864 y 1886.

Durante la segunda mitad del siglo XIX el imperio Otomano se convierte en una nueva frontera objetivo de los apetitos colonialistas de las principales potencias europeas. Francia, que había ocupado Argel en 1830, se hará con el resto de Argelia y Túnez en 1881, Gran Bretaña recibe Chipre en 1878 y ocupa Egipto en 1882, Austria-Hungría obtiene Bosnia y Herzegovina en 1878 y Rusia parte de Anatolia ese mismo año. El interés suscitado por la situación política, unido a toda una serie de factores económicos, sociales o culturales, hará que varios diplomáticos españoles destinados en el Mediterráneo oriental vayan más allá de los informes que en- 
viaban al Ministerio de la Guerra. En estas circunstancias, a través de las crónicas periodísticas o de la publicación de sus memorias aportarán un nuevo punto de vista de la cuestión de Oriente al mundo del español ${ }^{1}$.

Hay que tener en cuenta que a lo largo de toda la cuestión de Oriente las relaciones hispano-otomanas fueron más que cordiales, eso sí, con alguna que otra pequeña crisis ${ }^{2}$. Mahmud II había reconocido a Isabel II en 1833, integrándose ambos en la órbita de la Europa Liberal que apoyó a los turcos en la guerra de Crimea contra la agresión rusa. El general Prim y otros destacados militares españoles fueron enviados como observadores y prestaron un cierto apoyo a la coalición pro-otomana. Pocos años más tarde, en 1860, la guerra de Maruecos y posterior conquista de Tánger y Tetuán, ensalzó los ánimos patrios, especialmente cuando en el verano de ese mismo año la revuelta en el Líbano y Siria se saldó con la masacre de numerosos cristianos y la devastación de muchos lugares de culto, como el convento español de Damasco. España había hecho un intento por recuperar el protagonismo político participando en la expedición francesa en Indochina en 1858 y entre 1861 y 1864 Santo Domingo había vuelto a la corona. En estas circunstancias se comprende que muchos lectores hispánicos quisieran estar al tanto de la situación política otomana y que nuestros diplomáticos ejercieran también de cronistas.

Tras las paces de París de 1856 la Europa Liberal presionó a los otomanos para que agilizaran las reformas del Tanzimat, el cual propiciará una cierta estabilidad política que afectará a la economía, apareciendo en este momento los primeros bancos, mucho de ellos con capital francés, inglés, prusiano o austriaco. Los ecos de las noticias de los recursos del imperio Otomano también debieron de llegar a España. A pesar de que apenas hubo relaciones comerciales, a finales del siglo XIX se empezó a considerar contar con los sefardíes como intermediarios financieros, a través del sistema de capitulaciones.

El interés de la sociedad española fue escaso y básicamente sociocultural. Por una parte ya desde finales del siglo XVIII las turquerías habían popularizado el tema, añadiéndose posteriormente la fascinación por Egipto tras la campaña de Napoleón o el hecho que la Tierra Santa perteneciera a los turcos. Otro dato que hay que tener en cuenta es que durante la segunda mitad del siglo XIX nace el turismo, permitiendo a la burguesía europea llegar a Estambul por medio del Orient Express desde 1888 y a muchos otros puertos otomanos por medio de barcos a vapor franceses o austriacos. Así, las revistas ilustradas, las guías de viaje y las memorias de diplomáticos, especialmente estas últimas, permitían conocer la realidad cultural otomana aportando información de primera mano. No hay que olvidar que la 
misión de los diplomáticos era tanto representar a España como tenerla al corriente de lo qué pasaba en el lugar en que estaban destinados.

Dentro de ese interés cultural destacan dos campos: la arqueología y la literatura. A lo largo de la segunda mitad del XIX tienen lugar numerosas excavaciones en Anatolia, Siria, Líbano, Palestina y Egipto, cuyos hallazgos serán expuestos en museos europeos y trasmitidos a todo el mundo por medio de los catálogos o de la prensa. No hay que olvidar la utilización del tema de las ruinas en corrientes artísticas como la Ilustración o el Romanticismo. La literatura de viajeros por los territorios otomanos en español es escasa y tiene más valor documental que artístico, sin embargo, hay suficientes textos para probar qué sí hubo un interés en la realidad otomana. La influencia de las obras de viajeros franceses como Chateabriand o Lamartine es innegable, especialmente por la cantidad de ediciones que tienen estos dos autores en el mundo del español ${ }^{3}$, pero, lo que para los románticos galos era poco más que un decorado orientalista, para los españoles era un reencuentro con la realidad histórica nacional a través del contacto con los árabes y, especialmente, con los sefardíes, los cuales habían mantenido la identidad cultural española y se convierten en muchos casos mediadores entre el mundo otomano y el español, tanto para los diplomáticos como para muchos viajeros españoles o hispanoamericanos.

Durante los años 1860 coinciden bajo el mando de Antonio Bernal de O'Reilly, Cónsul General en Siria y Palestina, Adolfo de Mentaberry y Adolfo de Rivadeneyra, los tres comparten una ideología liberal y el hecho de colaborar con diarios y revistas españoles.

Antonio Bernal de O'Reilly, es nombrado Cónsul General en Siria y Palestina en $1863^{4}$. El consulado español en Siria estaba situado en Beirut y durante su estancia atendía también a los asuntos en Palestina, lo cual le permitió conocer bien la zona tal como lo demuestran sus libros: Viaje a Oriente, en Egipto (1876) prologado por Mesonero Romanos; Jerusalén, la Semana Santa (1877); En el Líbano, cartas relaciones sobre la Siria y En Tierra Santa: la Judea la Samaria y la Galilea (1896). Paralelamente colaboró con $L a$ Epoca, diario del Partido Liberal, y es autor de varios libros sobre relaciones internacionales ${ }^{5}$. La primera parte de su Viaje a Oriente comienza con la salida de Madrid con dirección a Marsella, donde se embarca con destino Egipto en compañía de Adolfo de Rivadeneyra en 1863. Alejandría estaba conociendo un despertar económico al ser el punto de expedición del algodón. La Guerra Civil americana (1861-1865) había paralizado los envíos de este producto a Europa necesario para las industrias textiles. Por otra parte las obras del canal de Suez, inaugurado en 1869, estaban bastante avanzadas. Este canal iba a permitir a los españoles mejorar la comunica- 
ción con las posesiones en el Asia-Pacífico y Oceanía. En este contexto, Bernal describe tanto las ruinas de la que fuera ciudad clásica, como la situación de la Alejandría moderna con sus consulados, hoteles, teatros, cafés y paseos. El Viaje a Oriente, en Egipto tiene también una parte dedicada a El Cairo, con las consiguientes descripciones de las Pirámides, Heliópolis y el Nilo. Antonio Bernal aparece en el texto como un viajero moderno que describe monumentos, medios de transporte, posibilidades de diversión, a la par que aporta información sobre la sociedad egipcia como la situación del campesinado, la religión de los coptos o la Alejandría musulmana.

La personalidad del autor y protagonista del Viaje a Oriente se completa en Tierra Santa y en Siria, dejando de ser viajero para convertirse en representante de Isabel II. A la hora de comprender su misión diplomática hay que tener en cuenta dos hechos históricos, el primero fue la presencia española en la Guerra de Crimea (1854-1856) en el bando pro-otomano junto a franceses y británicos. El detonante de la contienda había sido la posesión de las llaves del la iglesia del Santo Sepulcro de Jerusalén. Rusia había apoyado las reivindicaciones de los ortodoxos frente a Francia que lo hacía con las de los latinos. El segundo es la guerra civil de 1860 en el Líbano y Siria entre cristianos y drusos y musulmanes. Como antes expuse, el convento español de Damasco fue saqueado y sus ocupantes asesinados. $\mathrm{Al}$ ser los otomanos incapaces de poner orden, Napoleón III había enviado su flota para pacificar la región. Poco después El Líbano adquiría un estatus de provincia autónoma cuyo gobernador era cristiano y contaba con el beneplácito de las potencias que firmaron las Paces de París de 1856. España fijó como indemnización la cantidad de 2.182.417 piastras en diciembre de $1860^{6}$ y Bernal fue el encargado de que se entregara el dinero al Estado español, haciendo valer sus derechos ante la Sublime Puerta y Roma, que no reconocía la pertenencia a España de dicho convento. No es de extrañar la importancia que reciben los franciscanos españoles en Tierra Santa, los cuales le reciben en Jaffa, aprovechando la ocasión para exponer su opinión del tema: «De todo esto se deducirá, que el Hospicio y conventos de Jaffa es de España; como pueden serlo los conventos, es del Patronato Real y bajo la protección de España, tanto más, cuanto que el guardián ha de ser español, según se manda por los Estatutos para el gobierno de la Santa Custodia, en el capítulo VI, artículo 68; yo también así lo creo, y nuestro gobierno lo cree, pero hay quien dice que no.. ${ }^{7}$ Tal y como afirmaba nuestro Cónsul los estatutos dejaban clara la nacionalidad del superior de este convento, así como de los existentes en Ramala, San Juan de Judea, Nicosia, Damasco y Estambul. Estas instituciones recibían fondos económicos de España, muchos de los cuales de la Corona. 
Representantes españoles en el imperio Otomano...

Al llegar a Jerusalén le recibe el Cónsul Francés. Antonio Bernal deja que su voz entre en el relato y que sean sus palabras las que permitan al lector conocer las relaciones entre estas dos naciones:

Señor Cónsul General, me dijo, Francia y España bellísimas gemelas que previsora unió la Divina Providencia, las dotó igualmente del mismo amor a Jesús Crucificado, para que ensalzadas con la misma efusión que hoy se ensalzan nuestras manos, fueran el baluarte inexpugnable de la fe. La una luchó bizarramente en estas tierras, la otra en tanto bravamente llevó a regiones más remotas la antorcha de luminosa que debía ahuyentar la oscuridad de las tinieblas, en que yacian mil pueblos por el paganismo separados, y hermanos hoy los vemos por sus creencias religiosas en el verdadero Dios que les dio su ser.

Las guerras santas de otros tiempos terminaron y hoy ambas naciones siempre unidas con los mismos vínculos, la una es la infatigable protectora de estos Santos Lugares, la otra su pródiga y constante bienhechora. ${ }^{8}$

Dentro de los viajes a Oriente se pueden diferenciar cuatro niveles, los cuales están presentes en la obra de Bernal de O'Reilly. Todo viaje supone un desplazamiento por el espacio, en este caso el itinerario incluye a España y Francia, punto de salida, Egipto, Palestina, Siria y el Líbano. Se trata también de un viaje a través del tiempo empezando en 1863 y terminado en la antigüedad tanto de Egipto como de la época de Salomón, constructor del primer templo de Jerusalén y rememorando los primeros siglos del cristianismos y el medioevo de los cruzados. Para poder acceder al pasado es necesario viajar a través de los textos y Bernal se sirve de la Bíblia, la obra de Herodoto para Egipto, Michaud para los cruzados y otros textos actuales para poder explicar la situación sociopolítica de los parajes que visitó. El cuarto nivel es el cultural. Se trata del más difícil de acceder ya que es necesaria una formación y una capacidad de análisis que no todos los viajeros tienen, ya que sus estadías son breves. El hecho de permanecer varios años le permitió acceder a este nivel, en el que predomina como rasgo distintivo la identidad religiosa. De hecho en 1860 había habido dos crisis una entre ortodoxos y latinos en Jerusalén por la custodia de las llaves del Santo Sepulcro y la guerra civil entre maronitas y drusos en la montaña libanesa. Todos ellos aparecen escritos en la obra de Bernal de O'Reilly junto a los musulmanes y judíos. Durante la guerra de Marruecos de 1860 la sociedad española había descubierto el origen español de los sefardíes, por lo que, varios años después, lógicamente Bernal de O’Reilly informaría a sus superiores del origen de muchos judíos otomanos, tal y como aparece en sus memorias: «En el corredor me esperaba una diputación de judíos de origen español y procedentes de las familias expulsadas en 1492 por Fernando V e Isabel la 
Católica, que de las tres clases en que se divide esta raza que habita Jerusalén, es la más numerosa y conserva adulterado el idioma español. Su objeto, después de los cumplidos de costumbre, era pedirme la protección de la reina Isabel, y nuevamente formar parte de la gran familia española.» ${ }^{9}$

El 4 de noviembre de 1865 Adolfo de Mentaberry es nombrado vicecónsul en Damasco de donde pasará a Estambul en 1867. Su carrera diplomática tuvo un tercer destino, China, del 3 de noviembre de 1869 hasta el 31 de diciembre de $1870^{10}$. Posteriormente regreso a Madrid y ocupó cargos menores de la administración.

Las vivencias de Mentaberry vieron la luz en dos libros, Viaje a Oriente, de Madrid a Constantinopla, en 1873 e Impresiones de un viaje a Chi$n a$ en $1876^{11}$. Ambos están prorrogados por dos políticos de primera fila: Antonio Canovas del Castillo y Manuel Silvela, responsable de su nombramiento. Desde Damasco, Estambul o China envió sus crónicas a $E l$ Contemporáneo (1860-64), La Política (1865), El Tiempo (1869), y posteriormente a La Ilustración de Madrid (1871) y La Ilustración española y Americana ${ }^{12}$ (1871-84) donde publicó, entre otros artículos, "Los maronitas» (1872), «Los metoalis» (1873) y "Patronato de la corona de España sobre los lugares píos de Tierra Santa» (1884).

El Viaje a Oriente, de Madrid a Constantinopla es uno de los textos más completos sobre la situación del imperio Otomano en español durante los años de 1860. Mentaberry dejó Madrid en febrero de 1866 y se dirigió en ferrocarril a de Hendaya, donde continuó hasta Marsella, sede de las Mensajerías Imperiales, en donde se embarca en el Said. Antes de llegar a Damasco hace escala en Egipto, donde describe Alejandría y El Cairo, Jaffa y Beirut. Antonio Bernal de O'Reilly, su superior en el Líbano, le recibe en Beirut y, finalmente, toma posesión de su viceconsulado en Damasco el 1 de marzo. Permaneció desde el 1 de marzo de 1866 hasta el 18 de julio de 1867, fecha en que le trasladan a Estambul con el cargo de primer secretario.

La personalidad del protagonista de De Madrid a Constantinopla es compleja. Nuestro vicecónsul no tenía experiencia en la diplomacia, contaba con unos veinticinco años de edad y no sabía árabe. Mentaberry era también un hombre de su época y en este texto se encuentran gran parte de las características del romanticismo: culto al yo, exotismo, admiración por el pasado histórico, sensiblería y predominio de la emoción sobre la razón, es decir, casi todo lo contrario de lo que se espera de un representante de nuestro intereses nacionales. Pero también hay que tener presente que la producción textual de Mentaberry se orienta hacia tres focos: los informes al ministerio, los artículos periodísticos y su obra literaria, es en este último donde se permite la exaltación de su yo romántico. 


\section{Representantes españoles en el imperio Otomano...}

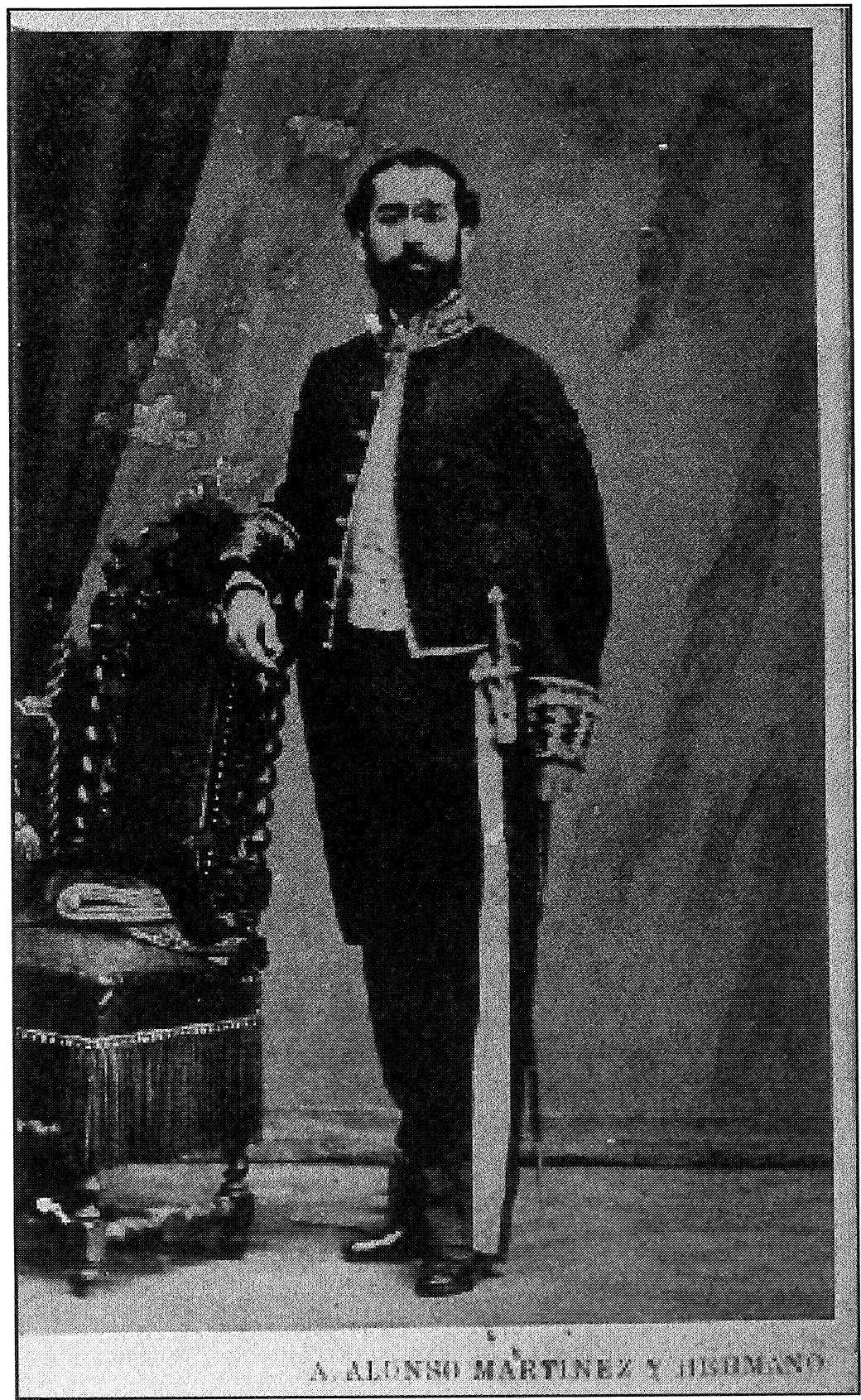

Figura 1. Adolfo de Mentaberry, fotografía de A. Alonso Martínez y Hermano 
La figura del diplomático destaca en lo referente a España. Así, se maravilla por el papel realizado por los franciscanos españoles en Jaffa, el puerto donde desembarcaban los peregrinos antes de ir a Jerusalén: «[...] todos van a hospedarse en este convento español de los padres franciscanos. Así España tiene en estas regiones un altísimo renombre de piadosa. Llámanla la católica, la muy católica, la privilegiada de Dios y es envidiada [...]». ${ }^{13}$ No hay que olvidar que los franciscanos habían sido la principal representación nacional en el imperio Otomano hasta las paces de 1783. Como era de esperar Mentaberry se hospedó en el convento de Damasco, dejándonos una retrato de su superior, el Padre Collado, y de la reconstrucción del mismo.

Mentaberry pasó de ser Vicecónsul en Damasco a Secretario de Primera en Estambul un año más tarde. Desde este destino se puede leer claramente su desazón por la falta de interés de España en la cuestión de Oriente, empezando por el estado de la Legación: «jcosas de España! desde entonces [su construcción] no se ha gastado un céntimo en reparaciones, a pesar de haber reclamado mil veces al ministerio del Estado nuestros representantes fondos al efecto, hallándose a la sazón en tal estado que únicamente tres salones quedaban habitables (1)» ${ }^{14}$. Mentaberry se queja de la falta de medios con que contaban, lo cual no permitía dar la imagen adecuada de la nación que representaban: «El caik [caique] de los embajadores es también de tres pares [de remos]; pero la legación de España no tiene uno tampoco, a pesar de que el gasto sería de 20.000 rs; pero el gobierno se niega siempre a darlos, y este detalle completa la inferioridad y el ridículo de nuestra posición aquí, pues no siendo decoroso alquilar un caik para las ceremonias oficiales, hay que ir de prestado.» ${ }^{15}$

Representación y romanticismo son compatibles en algunas ocasiones como la indignación por los sucesos de 1860 en Damasco en el cual se destruyó el convento español y asesinaron a los frailes. La imagen de los musulmanes reaparece durante el romanticismo, dotándoles en la mayoría de los casos de violencia, irracionalidad y odio a los cristianos: "[...] recordar la sangrienta hecatombe que costó la vida allí mismo a 1.400 desgraciados. Aquellos escombros están empapados en sangre y parecen humear todavía, clamando venganza ya que la tierra no les hizo justicia.» ${ }^{16}$ Otro ejemplo son las meditaciones románticas sobre el paso del tiempo, la coexistencia entre tradición y modernidad o la existencia de Dios ante la contemplación del paisaje. Uno de los mejores escenarios para plasmar estos pensamientos se produce en lo alto de la pirámide de Kéops: 
Representantes españoles en el imperio Otomano...

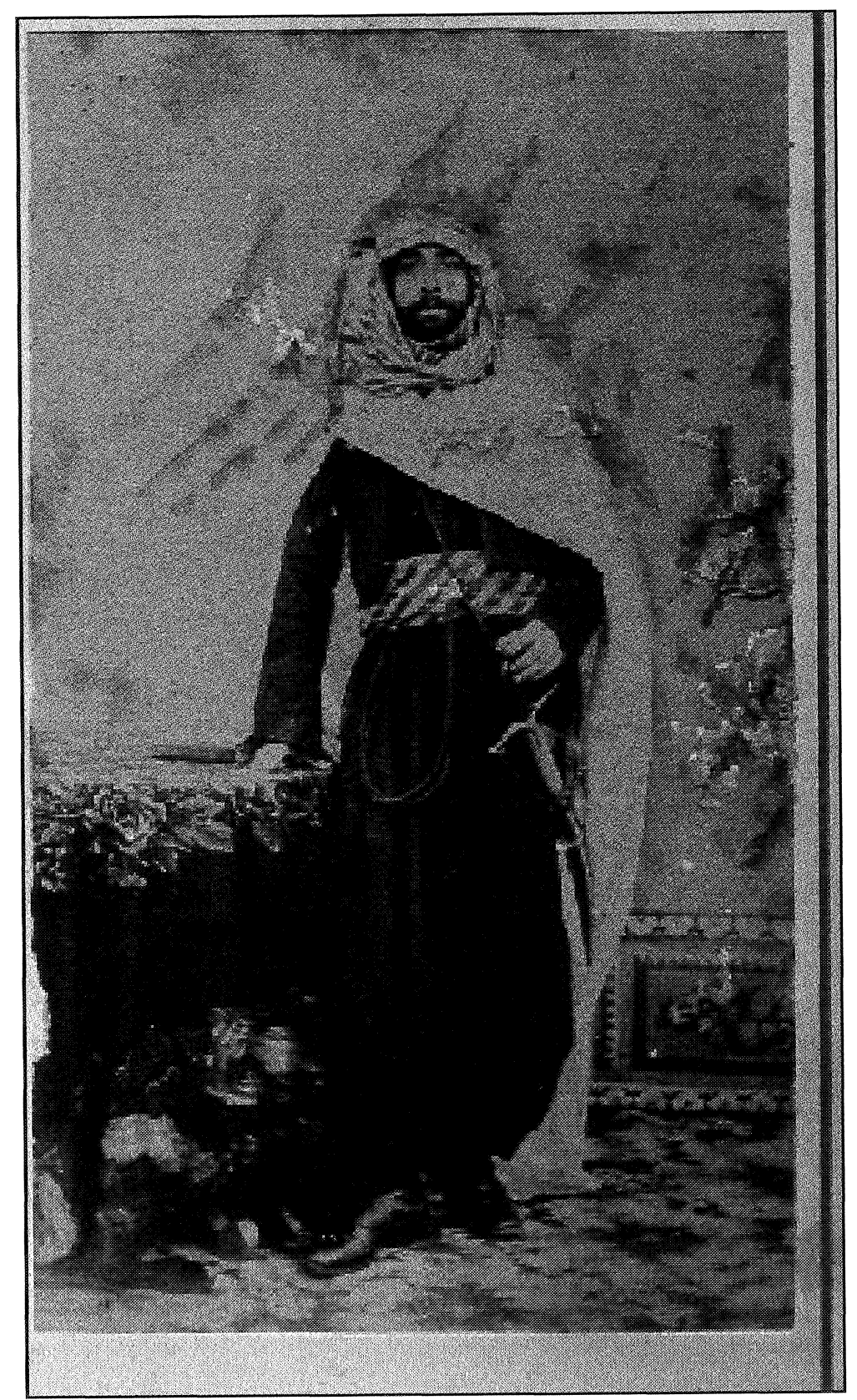

Figura 2. Adolfo de Mentaberry vestido de árabe 
Aquel pináculo, roto y destrozado por la destructora mano del hombre, forma una meseta donde el pie se asienta y la vista se derrama ansiosa por ancho horizonte, descubriendo la extensa llanura donde se dio la batalla de las Pirámides; al Sudoeste la esfinge de Armachis, llamada por el vulgo de Sesostris, que es de roca natural, cuya cabeza solamente es obra humana, pues el cuerpo es pura y simplemente una montaña, aparece del tamaño de un juguete, a pesar de que su altura es de 19 metros; la verdura del frondoso valle del Nilo, cuya cinta de plata reluce al sol, contrastando con la sábana ardiente del desierto; las afiligranadas relucientes torres de la ciudad y lejos la locomotora que silba, ondeando al viento su penacho de humo; las dragas que trabajan para abrir el canal de Suez, otro sueño de los faraones que a nuestra época tocaba realizar, poniendo en comunicación dos mares y acortando el camino de las Indias Orientales; la civilización moderna, en una palabra, ejecutando con sus poderosos medios de electricidad, pólvora, vapor e industria las grandes concepciones de la edad antigua.

¡Cuán pequeño se siente el hombre aquí! En su soberbia, se asomó a ver un abismo físico y encuéntrase, sin pensarlo suspendido entre dos abismos morales: la negación del caos y el infinito de la creación; el pasado y el porvenir del mundo; la obra de los hombres y la obra de Dios. ${ }^{17}$

Mentaberry, que a lo largo de su texto se muestra como un defensor del catolicismo, tiene momentos de duda sobre la existencia de Dios y de angustia existencial, otros dos elementos propios del Romanticismo. Otro de sus puntos de debilidad son las mujeres de la alta sociedad otomana: «Reclinadas en el fondo de sus coches, lucen lujosos trajes y las caras más bellas del mundo, a través de su entreabierto Ferayie y de su transparente yasmak, que en vez de velo pudoroso es blanca aureola que realza y hace más provocadora la mirada de sus fascinadores ojos negros.» ${ }^{18}$ Nuestro diplomático fantasea varias veces sobre el hecho de que el velo permitía a las otomanas la posibilidad de engañar a sus maridos y en más de una ocasión se refiere a la comunicación no verbal con ellas, a través de miradas apasionadas.

Adolfo de Mentaberry realizó en De Madrid a Constantinopla una de las mejores crónicas del Mediterráneo otomano que tenemos en español. En este momento se estaban desarrollando las principales ciudades portuarias como Alejandría, Beirut o Esmirna, puntos de contacto político, económico y cultural que describe a sus lectores hispánicos. Damasco y Estambul son las que mejor están tratadas, especialmente la capital otomana que conocía la llegada de fondos económicos europe- 
os, el nacimiento de la banca y de una naciente burguesía compuesta de judíos, armenios, griegos o levantinos, protegidos por las potencias. Mentaberry es uno de los primeros en dar noticia del origen español de los sefardíes otomanos, primero de los de Alejandría y posteriormente de los de Estambul y su papel en una sociedad otomana, especialmente en la banca como en el caso de la familia Camondo, ennoblecida por Víctor Manuel de Saboya a quien ayudaron a financiar las guerras de unificación italiana.

Otro de los cónsules destinados en Beirut que dejaron constancia de sus memorias es Manuel José Quintana en 1876. Un año más tarde publicó Siria y el Líbano. Este texto se acerca más a un trabajo de investigación que a la literatura de viajeros. Siria y el Líbano tiene dos capítulos, uno dedicado al harem y otro al papel de la mujer citando el Corán $n^{19}$. De esta manera el lector tiene un acceso directo a la fuente y conoce tanto la parte negativa como los castigos físicos en caso de adulterio, como la positiva como la sura 4 del capítulo IV en la que Mahoma decía «Habladlas siempre un lenguaje dulce y honesto. ${ }^{20}$ Como se puede apreciar por la siguiente cita el tono de la obra es de comprensión y acercamiento a esta religión: «El Korán, según ellos, no es la palabra de Mahoma solamente, es la palabra de Dios revelada a Mahoma, transmitida por su boca al pueblo árabe. No permitiendo la índole de nuestro libro dar aquí una biografía extensa de Mahoma, apuntaremos, sin embargo, algunos de los principales hechos de la vida de aquel hombre extraordinario por más de un concepto.» ${ }^{21}$

Quintana logra en este texto una de las mejores descripciones de los pueblos de esta región aportando información sobre maronitas, drusos, metualis, ismaelitas, ansirinos, quemaceos, kurdos, samaritanos y jezidis. Incluso la descripción de este último pueblo, de lengua kurda, practicante de una religión con elementos del islam, cristianismo, zoroastrismo, paganismo, judaísmo y chamanismo ${ }^{22}$, está realizada de una manera moderna: «Los adoradores del diablo, cuya religión practican todos los jezidis, dicen que el mal, obra del diablo, predomina en todas las cosas y que esto mismo muestra el poder del diablo, al cual adoran para tenerlo propicio; además creen que el diablo volverá muy pronto al favor de Dios, sin perder por ello la maligna influencia que ejerce en la naturaleza.» ${ }^{23}$

La mayoría de los textos de Mentaberry, Rivadenyra, Bernal o Quintana se publican en la década de los años 1870. Como antes expuse, la descripción de prácticas y creencias religiosas es de vital importancia, tanto en los textos que se acercan al romanticismo, como al 
realismo, el estudio de Quintana o la memoria de de la Rada. Hay que tener en cuenta que la libertad de culto se produce en España en 1868, se revitalizó la vida cultural y la enseñanza y aparecieron numerosas sociedades científicas. Por otra parte la Restauración se caracteriza por tener una cultura liberal que creó un clima de tolerancia y libertad. ${ }^{24}$ Es en este momento cuando surgen los libros a los que me he referido.

Poco más tarde, en 1884 Diego de Coello de Portugal toma posesión de la legación española en Estambul. La trayectoria profesional de Diego de Coello está marcada por el servicio exterior, la política, en las filas del Partido Liberal, y el periodismo. Como diplomático había desempeñado el cargo de Ministro Plenipotenciario en Cerdeña, Bélgica, Suiza, Portugal e Italia. Durante estos destinos enviaba sus crónicas a publicaciones nacionales y extranjeras, llegando a colaborar con ocho al mismo tiempo entre otros: La Epoca, diario que él mismo había fundado en 1849, La Ilustración Española y Americana; Las Novedades de Nueva York; El Diario de Barcelona o El Diario de la Marina de la Habana. Coello llegó a Estambul pocos años más tarde de la guerra rusoturca de 1877-78 tras la cual los otomanos perdieron la mayoría de las provincias de los Balcanes. Desde Estambul y por medio de La Epoca y La Ilustración Española y Americana dio a conocer la situación de Turquía, la de los nuevos reinos balcánicos y la de los ingleses en Egipto y Sudán donde el General Gordon había sido abatido por las tropas del Madhi.

Cuando Coello llega al imperio Otomano Abdül Hamid II llevaba en el trono ocho años y todavía no se habían producido las masacres de armenios y de macedónicos que estremecieron a la opinión pública mundial. Coello, por cuestiones profesionales, estaba en contacto con él. En la última de sus "Cartas de Constantinopla» describe los sentimientos que el sultán tenía por España, aportando una nueva imagen de un soberano otomano muy diferente del imaginario español: "La muerte de Alfonso XII arrancó a Abdül-Hamid lágrimas que he visto asomar a sus ojos, y su corazón ha sabido apreciar las altas virtudes y nobilísimas cualidades de la noble señora que inspira el respeto y el amor de Europa. Cuando los terremotos de Andalucía conmueven todas las almas generosas, la del Sultán es la primera a socorrer tantos infortunios, enviando espontánea y rica ofrenda a mi patria. $»^{25}$ 


\section{Representantes españoles en el imperio Otomano...}

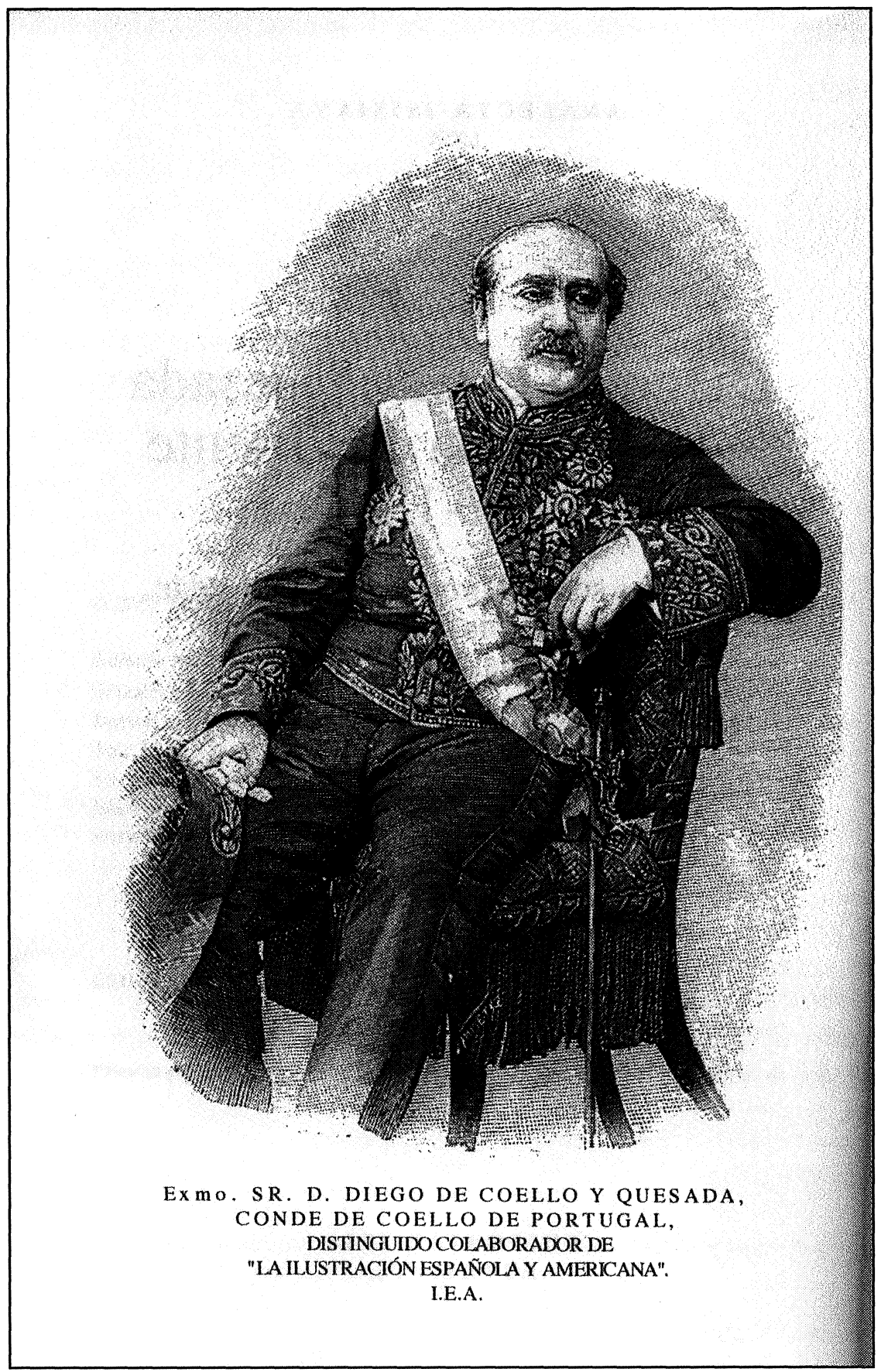

Figura 3. Diego de Coello de Portugal 
Coello describe la sociedad otomana fijando su atención en la forma en que se celebran las fiestas. Así, a través de las páginas de la Ilustración Española y Americana nos ha dejado una de las más bellas descripciones de Estambul durante el final del Ramadán y el Sacrificio de los Carneros. No sólo las fiestas musulmanas tienen lugar en sus crónicas, Coello también trata de las de los demás grupos confesionales otomanos presentes en Estambul, pudiendo leer entre líneas la defensa de la libertad de culto, uno de los caballos de batalla de los liberales y republicanos. Quiero terminar este artículo con esta cita que prueba el interés de una serie de diplomáticos y cronistas de carácter liberal en demostrar al mundo en español la situación otomana, haciendo hincapié en su esfuerzo por cambiar la imagen tradicional de los turcos en nuestra mentalidad.

Si como en este año acontece caen en los mismos días la Pascua de los católicos, armenios y griegos, coincidiendo con la de los hebreos, que ha sido a principio de esta semana, y como siempre reuniéndose el Viernes Santo con el día que los musulmanes consagran a sus oraciones, no es posible encontrar en ciudad alguna paisaje más pintoresco ni espectáculo de más animación y vitalidad.

Ayer, Viernes Santo mientras el muecín turco llamaba a la oración con un cántico verdaderamente notable por la voz, y desde el minarete de la nueva y linda mezquita que Abdül Hamid acaba de edificar dentro a su palacio quiosco de Yildiz, rodeándola de jardines; $y$ que centenares y centenares de damas turcas veladas iban en carruajes o caiques al celebrado sitio de las Aguas Dulces de Europa, el delegado apostólico monseñor Rotelli dirigía su bella voz italiana a los católicos reunidos en al catedral del Espíritu Santo durante el cántico de las Siete Palabras, el Patriarca Griego precidía la procesión en la nueva iglesia de la Santísima Trinidad, la Embajada rusa celebrada en la capilla de palacio las ceremonias de la Semana Santa, y el patriarca armenio católico, monseñor Azarian, descansaba del largo lavatorio de niños preciosamente vestidos que preside todos los años en el templo armenio de Santa María. ${ }^{26}$

\section{Notas}

1 Para tener una idea de la literatura e viajeros en español véase de LITVAK, L. (1986a) y (1986-b). Sobre los viajeros en Estambul véase mis libros (2003-a) y (2005). Para tener una idea de El Líbano y Damasco en textos en español durante la Cuestión de Oriente véanse mis libros (2003-b) y (2004-a).

2 Sobre las relaciones hispano-turcas puede consultarse de MARTín Asuero, P. (ed) (2003-b).

${ }^{3}$ Martín Asuero, P.(2004-b): 189-194. 
${ }^{4}$ Fue también Vicecónsul en Burdeos en 1844 de donde pasó a ser cónsul en Nantes en 1852 hasta que se trasladó a Beirut en 1863 hasta 1866 más tarde abandono la carrera diplomática hasta 1875 que fue nombrado cónsul en Bayona hasta marzo de 1881, Archivo del Ministerio de Asuntos Exteriores legajo 28, n 1149.

5 García-Romeral PÉrez, C. (1995): 61-62.

${ }^{6}$ García Barriuso, P. (1994): 545.

7 Bernal De O'REILly, A. (1896): 25.

8 Bernal DE O'REILLY, A. (1896): 54.

9 Bernal De O'Reilly, A. (1896): 87.

10 Archivo del Ministerio de Asuntos Exteriores de Madrid, legajo P 172, 08998.

11 Este tema lo he tratado en "Adolfo de Mentaberry», Bilbao, Escala, No 3, pp 2835, reeditado en MARTín Asuero, P. (2003-a) 21-31 y «Adolfo de Mentaberry en Damasco", Cervantes, $\mathrm{N}^{\circ} 3$ (2003-c) 43-67.

12 García-Romeral Pérez, C. (1995): 168.

13 Mentaberry, A. (1873), 92.

14 (1) Después se ha hundido del todo y así continúa. MentaberRy, A. (1873): 452.

15 Mentabery, A. (1873): 466.

16 Mentabery, A. (1873): 254.

17 MentaberRy, A. (1873): 79-80.

18 MentaberRy, A. (1873), p. 492.

19 Capítulo IV, suras 1, 3, 4, 13, 14, 24, 26, 27, 28, 30; capítulo XXIV, suras 32-8; capítulo XVIII, sura 17, QUINTANA, M. (1877): 162-165.

20 Quintana, M. (1877): 162.

21 Quintana, M. (1877): 168-169.

22 Planhol, X. de (1997): 178.

23 Quintana, M. (1877): 154.

24 Fusi, J.P. y PALAFOX, J. (1998): 155.

25 Martín Asuero, P. (ed-a). (2003). 188. «El Sultán Abdul-Hamid», fue publicado en La Epoca el 18 de julio de 1886.

${ }^{26}$ Martín Asuero, P. (ed-a). (2003). 166.

\section{Bibliografía}

Bernal De O'ReIlly, A. (1877): Jerusalén, la Semana Santa. Lamaignère, Bayona.

Bernal de O'ReIlly,, A. (1878): Viaje a Oriente, en Egipto. Victoriano Suárez, Madrid. Bernal de O'Reilly, A. (1888): En el Líbano. Biblioteca Popular Ilustrada, Madrid. Bernal De O'Reilly, A. (1898): En Tierra Santa. Hijos de R. Baroja, San Sebastián.

Fusi J. P. y PALAFoX, J. (1998): España: 1808-1996. El desafio de la Modernidad. Espasa, Madrid.

GARCÍA BARrIUSO, P. (1992): España en la historia de Tierra Santa. Ministerio de AA.EE., Madrid.

García-Romeral PÉrez, C. (1995): Bio-bibliografía de Viajeros Españoles (siglo XIX). Ollero \& Ramos, Madrid.

LITVAK, L. (1986-a): El ajedrez de estrellas, crónica de los viajeros españoles en el siglo XIX por países exóticos (18s00-1913). Laila, Barcelona. 


\section{Pablo Martín Asuero}

LITVAK, L. (1986-b): El sendero del tigre, exotismo en la literatura española de finales del siglo XIX. Taurus, Madrid.

MARTÍn ASUERo, P. (2003-a): Estambul, el ejército otomano y los sefardíes en textos en español. Isis, Estambul.

MARTín Asuero, P. (2003-b): España y el Líbano, 1788-1910. Miraguano, Madrid.

MARTín Asuero, P.(2004-a): Descripción del Damasco Otomano (1807-1920). Miraguano, Madrid.

MARTÍN ASUERo, P. (2004-b): Le voyage en Orient de Lamartine, sa traduction en espagnole et son influence sur des auteurs hispaniques, Actes du Colloque International Lamartine. Universidad del Egeo, Izmir. pp 189-194

MARTín AsUERo, P. (2005): Viajeros hispánicos en Estambul, de la Cuestión de Oriente al reencuentro con los sefardies (1784-1918). Isis, Estambul.

Martín Asuero, P.(ed) (2003-a): Diego de Coello Quesada y la Cuestión de Oriente. Isis, Estambul.

MARTÍN AsUeRo, P (ed). (2003-b): España-Turquía, del enfrentamiento al análisis mutuo. Isis, Estambul.

MENTABERRY, A. (1874): Viaje a Oriente, de Madrid a Constantinopla. Berenguillo, Madrid.

Planhol, X. (1997): Minorités en Islam. Flammarion, París.

QuinTANA, M. (1877): Siria y Líbano. Madrid. 